\title{
PREDICTED DEVELOPMENT OF THE CITY OF NITRA IN SOUTHWESTERN SLOVAKIA BASED ON LAND COVER-LAND USE CHANGES AND SOCIO-ECONOMIC CONDITIONS
}

\author{
HALADOVÁ, I. ${ }^{1}-$ PETROVIČ, F. ${ }^{2 *}$ \\ ${ }^{1}$ Institute of Landscape Ecology, Slovak Academy of Sciences \\ Štefánikova 3, 814 99, Bratislava, Slovak Republic; e-mail: ivana.haladova@savba.sk \\ ${ }^{2}$ Constantine the Philosopher University in Nitra, Faculty of Natural Sciences, Department of \\ Ecology and Environment, Tr. A. Hlinku 1, 949 74, Nitra, Slovak Republic \\ *Corresponding author \\ e-mail:fpetrovic@ukf.sk \\ (Received $13^{\text {th }}$ Feb 2017; accepted $20^{\text {th }}$ Jul 2017)
}

\begin{abstract}
The aim of this paper is to predict possible future development of the city of Nitra, southwestern Slovakia. We proposed three scenarios of possible further development of the city (negative, progressive and realistic) based on mapping and evaluation of land cover and land use changes in Nitra from 1949 to 2015. Also taking into account the socio-economic development of the city with an emphasis on the current state and recent changes. The SWOT analysis in three domains (social, economic, environmental) was prepared and used for scenario development as well. The spreading of a built-up area is a natural consequence of city development. It is connected with processes of urbanization and industrialization that are accompanied with loss of agricultural land. Changes caused by these processes are clearly visible in Nitra and also within its vicinity. The structure of land use development has varied over the years. At the beginning of the period studied, changes connected with agriculture production dominated, while presently, the changes that prevail are connected with urbanization and industrialization.
\end{abstract}

Keywords: CORINE, future development prediction, scenario approach, SWOT analysis

\section{Introduction}

All the important driving forces of landscape changes are related to the population growth and the lifestyle becoming increasingly more urban and more mobile (Antrop, 2005). Spreading of the urban area accompanied with urban population growth and economic development is a global trend. Urbanization causes land cover and land use changes that are usually related to economic growth. As a country moves from a ruralagricultural base to an urban-industrial base, urbanization and economic development go hand in hand (Davis and Henderson, 2003). The pace and magnitude of landscape changes depends upon increasingly faster technological innovations and societal changes (Antrop, 2000). Therefore, the urban landscape is a result of mutually connected economic, demographic, socio-cultural, political, technological and environmental processes that are shaping its character (Ira, 2011). One of the consequences of urbanization is soil sealing, which is a change from agricultural, forest or other semi-natural or natural landscape into an urban and industrial landscape. This includes areas covered with buildings and infrastructure, urban greenery or sport and leisure facilities (EEA, 2015).

Understanding of landscape changes requires a sound understanding of the underlying processes that can be triggered by different driving forces (Hersperger and Bürgi, 2009). Papers focused on land cover changes and their driving forces in Central 
and Eastern Europe were published by e. g. Skokanová et al. (2012), Jarský and Pulkrab (2013), Lieskovský et al. (2013), Hartvigsen (2014), Kanianska et al. (2014), Munteanu et al. (2014) Smiraglia et al. (2015), Lima et al. (2016), Opršal et al. (2016) and Skokanová et al. (2016).

The structure of a cultural landscape is largely determined by human decisions - by direct or indirect impacts of human activities. In Europe, the human impact is mainly determined by agriculture but differs from region to region (Mander and Jongman, 1998). Nitra is situated in a major agricultural area of the Slovak Republic. That is why the agricultural land is most affected by changes in the study area. Changes in cultural and agricultural land in Slovakia were mapped by e. g. Ot’ahel et al. (2012), Ivanová (2013), Tarasovičová et al. (2013), Lieskovský et al. (2014) and Kopecká et al. (2015).

The study area includes urban areas and also agricultural and forest areas. Because of that, the landscape structure of the study area is considerably diversified and types of changes are quite numerous. Land cover and land use in Nitra were mapped by various authors, e. g. Bugár et al. (2006), Mišovičová (2008), Hreško et al. (2015) and Haladová and Petrovič (2015).

The aim of this paper is to propose scenarios of further possible development of the city based on mapping and evaluating of the land cover and land use changes in Nitra and two surrounding villages from 1949 to 2015, taking into account the socioeconomic development of the city with an emphasis on the current state.

\section{Materials and Methods}

\section{Study area}

The study area consists of the cadastral areas of Nitra and the villages Lužianky and Ivanka pri Nitre. The size of the studied area is 12304.73 ha.

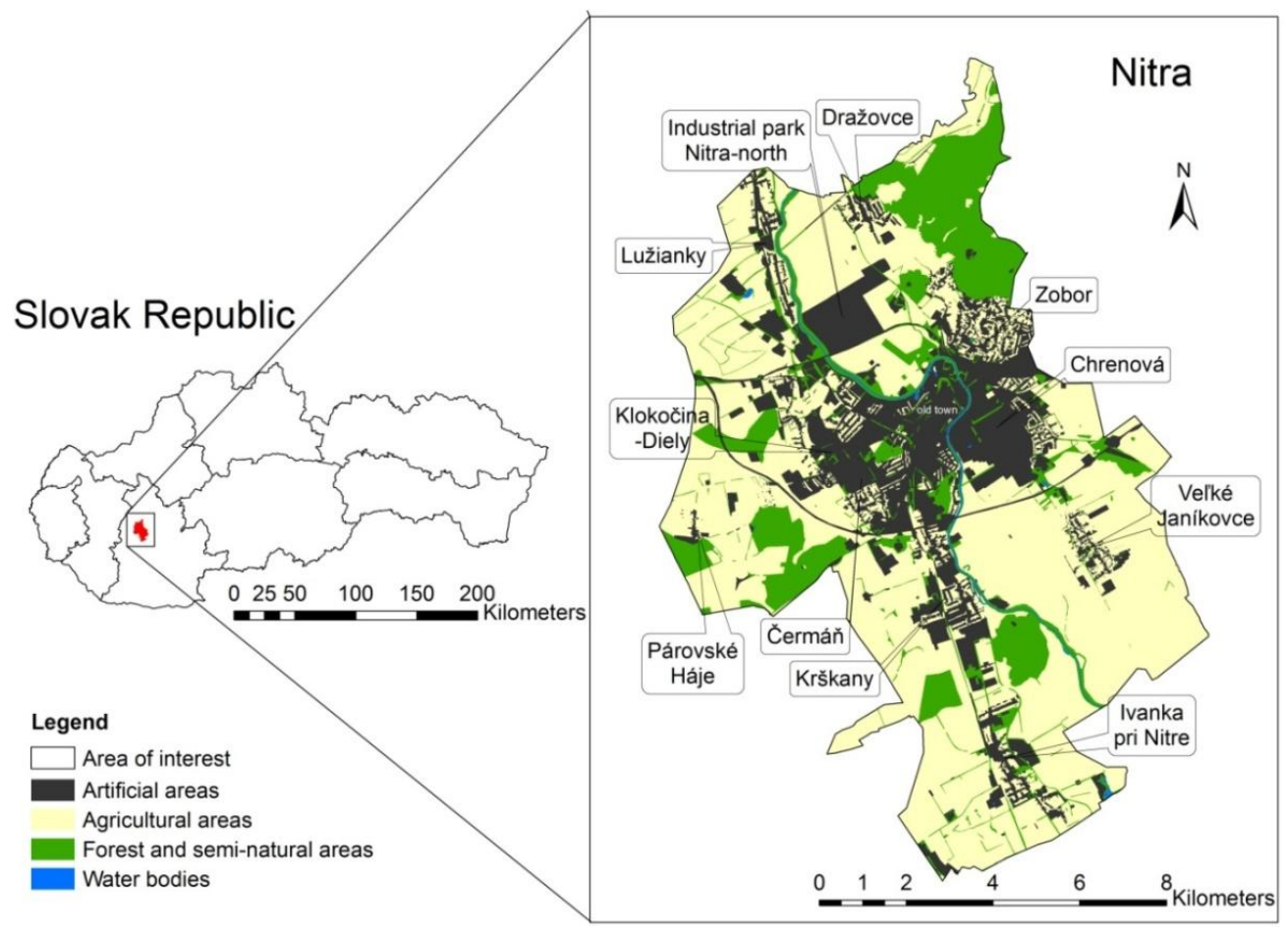

Figure 1. Location of the study area within the Slovak Republic 
Nitra is the capital of Nitra county and Nitra district. It is situated in the southwestern part of Slovakia, on the border of the Tríbeč mountain range and the Podunajská lowland (Fig. 1). This location creates specific conditions suitable for the development of agriculture, industry and forestry. Agriculture has a long tradition in this region. However, it has declined over the past few years, especially viniculture and fruit growing mainly due to the urbanization and industrialization. Thanks to the R1 expressway, the development of industry is supported by good traffic connections, especially with the western and central areas of Slovakia.

\section{Methods}

We evaluated the size of land cover classes in five years (1949, 1974, 1990, 2003 and 2015) and changes to their size between these years.

We used the map layers of land cover for the years 1949, 1990 and 2003 created for the publication Landscape of Nitra and its surroundings (Hreško et al., 2006). However, we changed classification legend of landscape classes in these layers, to unify the legend used in all layers. This new classification was created by Petrovič et al. (2009).

Then we created map layers of land cover for the years 1974 and 2015. We prepared the map layer for the year 1974 by analysis of aerial photographs provided by the Topographic institute of the Slovak Republic; the layer for the year 2015 by analysis of aerial photographs made in 2010 (provided by EUROSENSE Slovakia and GEODIS Slovakia), free satellite images (Google maps, Bing maps, Mapy.cz) and field survey.

For classification, we used the first and third levels of legend to the CORINE land cover methodology (Heymann et al., 1994; Bossard et al., 2000). The third level distinguishes 44 classes, in the first level, this methodology has five basic classes:

- Artificial areas

- Agricultural areas

- Forest and semi-natural areas

-Wetlands

- Water bodies

For spatial data processing and creating of map layers we used ArcGIS 10.1 software.

We calculated the area of land cover classes for each year. Then we evaluated changes between the years using multi-temporal analysis, when we merged all data about land cover classes in all studied years into one layer and then we compared their size.

We evaluated land use changes by a six-digit code, where the first three digits represent codes of land cover from one year and the next three digits represent land cover from the next year. Every six-digit code was assigned to the type of change based on the methodology created by Cebecauerová (2007). We added two new types of changes - Forest management $(\mathrm{F})$ and Overgrowing $(\mathrm{O})$ to this classification.

We identified a total of 17 types of changes in the study area:

- Increase of woody vegetation (a) - planting of new forests, planting of alleys and so on

- Increase of woody vegetation, loss of agricultural land (a L)

- Loss of woody vegetation (D) - any loss of wooded areas, such as cutting down a forest, an alley or park vegetation, which is followed by the creation of meadows or grasslands 
- Extensification of agriculture (e) - big and heavily agriculturally used fields being transformed into meadows, abandoned grassy areas or agriculturally used gardens

- Forest management $(\mathrm{F})$ - cutting down a forest to plant a new forest or forest nursery

- Intensification of agriculture (i) - transformation from meadows or small fields (narrow-strip fields) into big, heavily agriculturally used fields

- Intensification of agriculture, loss of woody vegetation (i D)

- Overgrowing (O) - spontaneous growth of shrubs and trees in abandoned areas

- Overgrowing, loss of agricultural land (O L)

- Remediation $(\mathrm{R})$ - process of demolishing built-up areas and their transformation into some kind of vegetation; for example, alley, park, meadow or abandoned area with shrubs and trees

- Industrialization $(\mathrm{t})$ - process of constructing factories, industrial parks, sewage treatment plants or any technical objects.

- Industrialization, loss of woody vegetation (i D)

- Industrialization, loss of agricultural land (t L)

- Urbanization (u) - construction of family houses, construction of blocks of apartments, creation of playgrounds, gardens around family houses and so on

- Urbanization, loss of woody vegetation (u D)

- Urbanization, loss of agricultural land (u L)

- Other changes/Unclassified (oz) - very small changes within the higher level of classification

These types of changes are generalized and one type of change may contain several variations of a specific change.

A lot of areas remained unchanged and were classified as Unchanged area (bz).

We divided landscape elements into five degrees of land use intensity according to Olah et al. (2009). Every group was assigned coefficient from 1 to 5:

1 - Very low land use intensity (tree vegetation, bedrock baring and raw soils, water bodies)

2 - Low land use intensity (shrub vegetation, young forest)

3 - Medium land use intensity (clearings, grass-herbal vegetation, patterns of agriculture land)

4 - High land use intensity (intensively cultivated agricultural land, residential greenery)

5 - Very high land use intensity (built-up and urban areas)

For determination of range and trend of changes, we calculated the intensity of land use and its changes during the studied years according to Olah et al. (2009). We calculated partial changes of land use intensity from the difference between coefficients of landscape elements (Eq. 1). A positive value indicates an increase of land use intensity (intensification) and a negative value indicates a decrease of land use intensity (extensification).

The overall relative change of land use intensity is expressed as the sum of partial changes using the equation:

$$
I_{R}=i_{2-1}+i_{3-2}+\ldots i_{m-n}
$$


where: $I_{R}=$ relative change of intensity of land use, $i_{2-1}=$ partial intensity of change between the second and first time horizon.

The resulting values may vary in range from -4 to +4

The absolute intensity of change reflects the sum of absolute values of partial changes. Which means, that it disregards their direction (intensification or extensification). The resulting values are therefore always positive. Through the absolute change of land use intensity we are able to identify areas in landscape that were affected by changes the most. We are also able to quantify number of these changes.

We also evaluated socio-economic data that has influenced land cover over the studied years. Socio-economic data was seen as a driving force of land cover changes. As a part of socio-economic analysis, we elaborated SWOT analysis for Nitra, focused on the current state of social, economic and environmental indicators.

We finally created three scenarios of possible city development in the next 20 years based on the acquired information.

\section{Results}

\section{Development of land cover and land use intensity in the city of Nitra during the period 1949 to 2015}

Agricultural land dominated throughout all of the years studied. However, its size decreased over the whole period. On the other site, artificial areas increased. Forest and semi-natural areas changed their size very slightly during the studied period. Water bodies covered less than $1 \%$ of the area in all studied years. Wetlands were located in the area only in 1949. Information about the percentage of land cover classes in each of the studied years is shown in Table 1 .

Table 1. Percentage of land cover classes in studied years, first level of classification

\begin{tabular}{c|c|c|c|c|c}
\hline & $\mathbf{1 9 4 9}$ & $\mathbf{1 9 7 4}$ & $\mathbf{1 9 9 0}$ & $\mathbf{2 0 0 3}$ & $\mathbf{2 0 1 5}$ \\
\hline Artificial areas & 7,13 & 13,75 & 16,74 & 18,12 & 23,45 \\
Agricultural areas & 71,67 & 69,61 & 68,37 & 63,48 & 58,89 \\
Forest and semi-natural areas & 20,18 & 16,09 & 14,27 & 17,88 & 17,15 \\
Wetlands & 0,15 & 0,00 & 0,00 & 0,00 & 0,00 \\
Water bodies & 0,87 & 0,55 & 0,61 & 0,52 & 0,51 \\
\hline
\end{tabular}

In the year 1949, $76.61 \%$ of the area had medium land use intensity, $10.04 \%$ of the area had very low, $7.37 \%$ of the area had very high and $5.97 \%$ of the study area had high land use intensity.

In the year 1974, $66.39 \%$ of the area had high land use intensity, $10.83 \%$ of the area had very low, $10.40 \%$ of the area had very high, $9.38 \%$ of the area had medium and $3.00 \%$ of the area had low land use intensity.

In the year 1990, $65.08 \%$ of the area had high land use intensity, $13.50 \%$ of the area had very high, $12.23 \%$ of the area had very low, $8.39 \%$ of the area had medium and $0.81 \%$ of the area had low land use intensity. 


$$
\text { - } 992 \text { - }
$$

In the year 2003, $65.06 \%$ of the study area had high land use intensity, $14.07 \%$ of the area had very high, $11.29 \%$ of the area had very low, $5.41 \%$ of the area had medium and $4.17 \%$ of the study area had low land use intensity.

In the year 2015, $61.09 \%$ of the study area had high land use intensity, $18.89 \%$ of the area had very high, $10.96 \%$ of the area had very low, $4.66 \%$ of the area had medium and $4.40 \%$ of the area had low land use intensity.

Comparison of land use intensity during the studied years is shown in Figure 2.

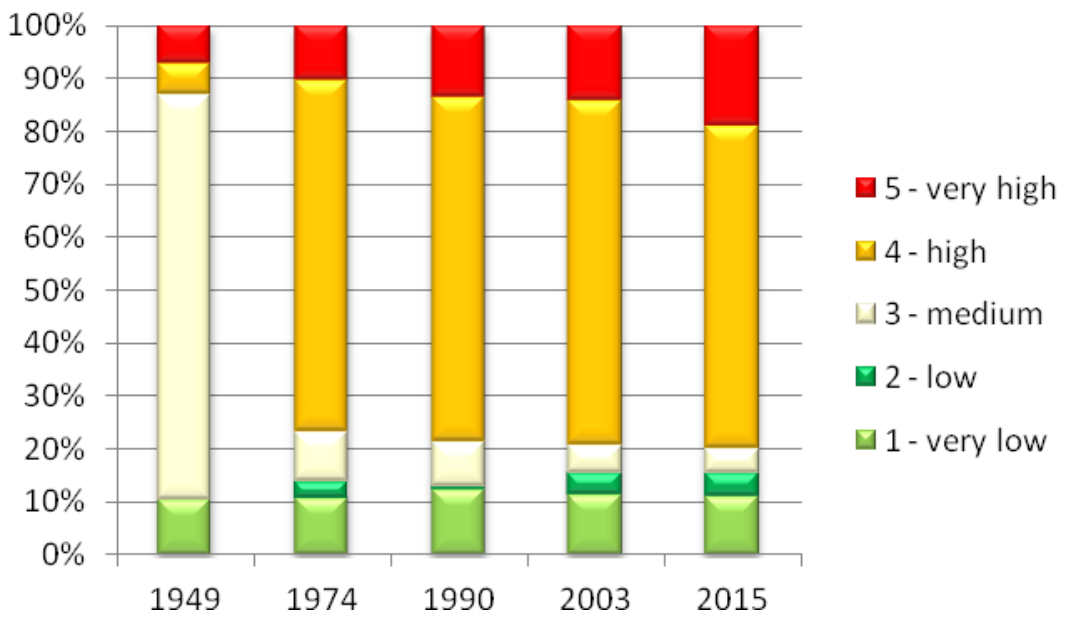

Figure 2. Intensity of land use during the studied years

\section{Changes of land cover and land use intensity}

Period 1949-1974

Between the years 1949 and 1974, 80.07\% of the study area was changed and $19.03 \%$ of the area remained unchanged. Information about the extent of all types of changes is in Table 2.

Table 2. Types of changes between the years 1949-1974

\begin{tabular}{|c|c|c|c|c|c|c|c|c|}
\hline 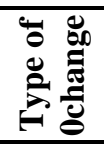 & $\stackrel{8}{2}$ & 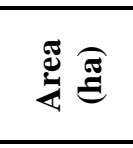 & 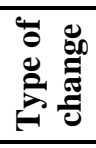 & $\stackrel{d}{4}$ & 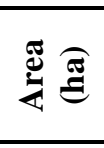 & 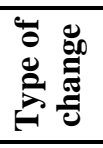 & $\stackrel{d}{2}$ & 选 \\
\hline $\mathbf{a}$ & 1.36 & 167.44 & i D & 0.26 & 32.54 & $\mathbf{t}$ & 0.34 & 42.03 \\
\hline a L & 2.50 & 303.40 & O & 0.78 & 95.83 & t D & 0.01 & 1.28 \\
\hline bz & 19.03 & $2,341.94$ & O L & 0.04 & 4.61 & t L & 2.46 & 303.07 \\
\hline D & 0.61 & 75.08 & $\mathbf{o z}$ & 1.10 & 135.27 & $\mathbf{u}$ & 0.86 & 106.39 \\
\hline e & 1.25 & 153.39 & $\mathbf{R}$ & 1.35 & 165.77 & u D & 0.03 & 3.09 \\
\hline $\mathbf{F}$ & 0.57 & 70.63 & $\mathbf{R} \mathbf{a}$ & 0.05 & 5.94 & u L & 5.72 & 703.49 \\
\hline $\mathbf{i}$ & 60.07 & 7393.16 & $\mathbf{R i}$ & 1.51 & 185.32 & $\mathbf{Z}$ & 0.14 & 16.95 \\
\hline
\end{tabular}

$\mathbf{a}$ - Increase of woody vegetation, $\mathbf{a} \mathbf{L}$ - Increase of woody vegetation, Loss of agricultural land, $\mathbf{D}$ - Loss of woody vegetation, $\mathbf{e}$ - Extensification of agriculture, $\mathbf{F}$ - Forest management, $\mathbf{i}$ - Intensification of agriculture, i D - Intensification of agriculture, Loss of woody vegetation, $\mathbf{O}$ - Overgrowing, $\mathbf{O} \mathbf{L}$ Overgrowing, Loss of agricultural land, $\mathbf{R}$ - Remediation, Recultivation, $\mathbf{t}$ - Industrialization $\mathbf{i} \mathbf{D}$ Industrialization, Loss of woody vegetation, $\mathbf{t} \mathbf{L}$ - Industrialization, Loss of agricultural land, $\mathbf{u}-$ Urbanization, u D - Urbanization, Loss of woody vegetation, u L - Urbanization, Loss of agricultural land, oz - Other changes/Unclassified 
The biggest change was intensification of agriculture (i), which affected $60.07 \%$ of the area. On the other hand, extensification of agriculture (e) affected only $1.25 \%$ of the area. Changes to agricultural land were connected mainly with collectivization and nationalization of private property. Urbanization on agricultural land $(\mathrm{u} L)$ affected $5.72 \%$ of the area. A large influence on the urbanization process was the construction of the Chrenová housing development. Remediation of unfit constructions on the border of city centre caused a remediation $(\mathrm{R})$ process that affected $1.35 \%$ of the area. Remediation connected with intensification of agriculture $(\mathrm{R} i)$ affected $1.51 \%$ of the area and industrialization on agricultural land ( $\mathrm{t}$ L) affected $2.46 \%$ of the area. The largest factory built in this period was Plastika. Other changes (oz) and changes smaller than $1.00 \%$ of the area affected $3.63 \%$ of the study area.

Intensity of land use changed $79.52 \%$ of the area. Intensification affected $68.91 \%$ of the area and extensification affected $10.60 \%$ of the study area.

\section{Period 1974-1990}

Between the years 1974 and 1990, $18.35 \%$ of the study area was changed and $81.65 \%$ of the area remained unchanged. Information about the extent of all types of changes is shown in Table 3.

In this period the construction of the Chrenová housing development continued and the construction of two new housing developments - Klokočina and Diely - started. The exhibition center Agrokomplex was also built in this period. This is why urbanization was the most extensive change that affected $2.48 \%$ of non-agricultural land (u) and $3.09 \%$ of agricultural land (u L). Intensification of agriculture (i) affected $2.70 \%$ of the area and in $1.89 \%$ of the area, tree and shrub vegetation was cut down for the purpose of creating new agricultural land (i D). On the other hand, extensification of agriculture (e) affected $2.33 \%$ of the area. Industrialization affected $0.99 \%$ of the area on agricultural land $(\mathrm{t} \mathrm{L})$ and $0.77 \%$ of the area on non-agricultural land $(\mathrm{t})$. Increase of woody vegetation (a) affected $1.14 \%$ of the area. Other changes (oz) and changes smaller than $1.00 \%$ of the area affected $2.96 \%$ of the area.

Table 3. Types of changes between the years 1974-1990

\begin{tabular}{|c|c|c|c|c|c|c|c|c|}
\hline 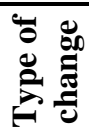 & $\stackrel{5}{2}$ & 预 & 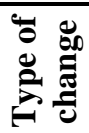 & $\stackrel{d}{d}$ & 递 & 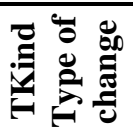 & $\stackrel{8}{8}$ & 选 \\
\hline $\mathbf{a}$ & 0.77 & 94.86 & i D & 1.89 & 232.24 & $\mathbf{t}$ & 0,73 & 89,58 \\
\hline a $\mathbf{L}$ & 0.37 & 45.83 & $\mathbf{O}$ & 0.01 & 0.81 & tD & 0,04 & 5,26 \\
\hline bz & 81.65 & $10,047.65$ & O L & 0.02 & 2.98 & t L & 0,99 & 121,5 \\
\hline D & 0.05 & 6.41 & $\mathbf{o z}$ & 1.27 & 156.03 & $\mathbf{u}$ & 2,36 & 290,22 \\
\hline e & 2.33 & 286.12 & $\mathbf{R}$ & 0.38 & 46.29 & u D & 0,12 & 14,28 \\
\hline $\mathbf{F}$ & 0.55 & 67.08 & $\mathbf{R} \mathbf{a}$ & 0.02 & 2.55 & $\mathbf{u} \mathbf{L}$ & 3,09 & 380,26 \\
\hline i & 2.70 & 332.24 & $\mathbf{R} \mathbf{i}$ & 0.49 & 60.55 & $\mathbf{Z}$ & 0,18 & 21,71 \\
\hline
\end{tabular}

a - Increase of woody vegetation, a $\mathbf{L}$ - Increase of woody vegetation, Loss of agricultural land, D Loss of woody vegetation, $\mathbf{e}$ - Extensification of agriculture, $\mathbf{F}$ - Forest management, $\mathbf{i}$ - Intensification of agriculture, i D - Intensification of agriculture, Loss of woody vegetation, O - Overgrowing, O L Overgrowing, Loss of agricultural land, $\mathbf{R}$ - Remediation, Recultivation, $\mathbf{t}$ - Industrialization i D Industrialization, Loss of woody vegetation, $\mathbf{t} \mathbf{L}$ - Industrialization, Loss of agricultural land, $\mathbf{u}-$ Urbanization, u D - Urbanization, Loss of woody vegetation, u L - Urbanization, Loss of agricultural land, oz - Other changes/Unclassified 


\section{Period 1990-2003}

Between the years 1990 and 2003, 13.02\% of the study area was changed and $86.98 \%$ of the study area remained unchanged. Information about the extent of all types of changes is in Table 4.

The most extensive type of change in this period was the intensification of agriculture (i) which affected $2.71 \%$ of the area. On the other hand, extensification of agriculture (e) affected $1.65 \%$ of the area. Increase of woody vegetation affected $2.34 \%$ of the area, mostly on agricultural land (a L). Changes to agricultural land were caused by the change of regime in 1989 and the following changes in ownership conditions. Changes in ownership conditions also caused remediation (R) on an area of $0.87 \%$. Urbanization ( $\mathrm{u}$ ) affected $2.02 \%$ of the area and industrialization $(\mathrm{t})$ affected $0.82 \%$ of the area. These changes were concentrated mainly at the end of this period, when the construction trends of big shopping malls and industrial parks began. Other changes (oz) and changes smaller than $0.50 \%$ of the area affected $3.48 \%$ of the area.

Table 4. Types of changes between the years 1990-2003

\begin{tabular}{|c|c|c|c|c|c|c|c|c|}
\hline 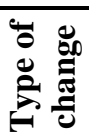 & $\stackrel{巳 e}{e}$ & 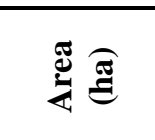 & 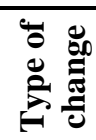 & $\stackrel{d}{2}$ & 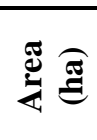 & 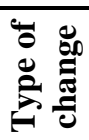 & $\stackrel{5}{4}$ & 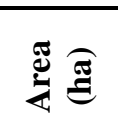 \\
\hline $\mathbf{a}$ & 0.15 & 18.25 & i D & 0.19 & 23.37 & $\mathbf{t}$ & 0.34 & 41.85 \\
\hline a $\mathbf{L}$ & 2.19 & 268.95 & $\mathbf{O}$ & 0.06 & 7.48 & tD & 0.01 & 0.95 \\
\hline bz & 86.98 & $10,703.27$ & O L & 0.24 & 29.81 & t L & 0.47 & 57.34 \\
\hline D & 0.61 & 74.69 & $\mathbf{o z}$ & 0.76 & 93.95 & $\mathbf{u}$ & 0.48 & 58.65 \\
\hline e & 1.65 & 202.61 & $\mathbf{R}$ & 0.55 & 67.34 & u D & 0.04 & 4.72 \\
\hline $\mathbf{F}$ & 0.88 & 107.68 & $\mathbf{R} \mathbf{a}$ & 0.06 & 7.41 & u L & 1.50 & 185.14 \\
\hline $\mathbf{i}$ & 2.52 & 310.52 & $\mathbf{R} \mathbf{i}$ & 0.26 & 32.54 & $\mathbf{Z}$ & 0.07 & 8.51 \\
\hline
\end{tabular}

a - Increase of woody vegetation, a L - Increase of woody vegetation, Loss of agricultural land, D - Loss of woody vegetation, $\mathbf{e}$ - Extensification of agriculture, $\mathbf{F}$ - Forest management, $\mathbf{i}$ - Intensification of agriculture, i D - Intensification of agriculture, Loss of woody vegetation, $\mathbf{O}$ - Overgrowing, $\mathbf{O} \mathbf{L}$ Overgrowing, Loss of agricultural land, $\mathbf{R}$ - Remediation, Recultivation, $\mathbf{t}$ - Industrialization i D Industrialization, Loss of woody vegetation, $\mathbf{t} \mathbf{L}$ - Industrialization, Loss of agricultural land, $\mathbf{u}-$ Urbanization, u D - Urbanization, Loss of woody vegetation, $\mathbf{u} \mathbf{L}$ - Urbanization, Loss of agricultural land, oz - Other changes/Unclassified

\section{Period 2003-2015}

Between the years 2003 and 2015, $9.08 \%$ of the study area was changed and $90.92 \%$ of the study area remained unchanged. Information about the extent of all types of changes is shown in Table 5.

This period is characterised by a significant loss of agricultural land due to the construction of industrial parks, big shopping malls and residential areas with family houses. The south town bypass (R1expressway) was also built in 2011. This is why the most significant kind of change was industrialization $(\mathrm{t})$ which affected $2.58 \%$ of the area. Urbanization on agricultural land ( $\mathrm{u} \mathrm{L}$ ) affected $1.77 \%$ of the area and urbanization on non-agricultural land (u) affected $0.88 \%$ of the area. Some of the areas lost their purpose and start to overgrow (O). This type of change affected $0.82 \%$ of the area. Other changes (oz) and changes smaller than $1.00 \%$ of the area affected $2.73 \%$ of the area. 
Table 5. Types of changes between the years 2003-2015

\begin{tabular}{|c|c|c|c|c|c|c|c|c|}
\hline 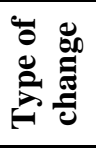 & 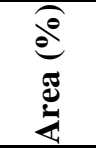 & 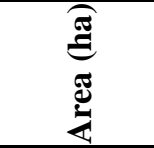 & 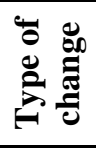 & 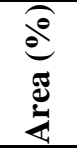 & 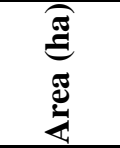 & 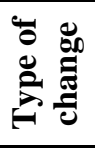 & 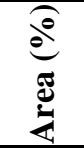 & 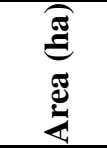 \\
\hline $\mathbf{a}$ & 0.11 & 13.00 & $\mathbf{i}$ & 0.16 & 19.65 & $\mathbf{t}$ & 0.26 & 31.44 \\
\hline a $\mathbf{L}$ & 0.13 & 15.63 & i D & 0.16 & 19.08 & t D & 0.08 & 9.38 \\
\hline bz & 90.92 & $11,188.23$ & $\mathbf{O}$ & 0.51 & 62.35 & $\mathbf{t} L$ & 2.51 & 308.34 \\
\hline D & 0.23 & 28.02 & O L & 0.37 & 45.60 & $\mathbf{u}$ & 0.77 & 95.16 \\
\hline $\mathbf{e}$ & 0.30 & 37.00 & $\mathbf{o z}$ & 1.18 & 144.98 & u D & 0.11 & 13.12 \\
\hline $\mathbf{F}$ & 0.38 & 46.72 & $\mathbf{R}$ & 0.08 & 10.34 & $\mathbf{u} \mathbf{L}$ & 1.77 & 217.31 \\
\hline
\end{tabular}

$\mathbf{a}$ - Increase of woody vegetation, a $\mathbf{L}$ - Increase of woody vegetation, Loss of agricultural land, D Loss of woody vegetation, $\mathbf{e}$ - Extensification of agriculture, $\mathbf{F}$ - Forest management, $\mathbf{i}$ - Intensification of agriculture, i D - Intensification of agriculture, Loss of woody vegetation, $\mathbf{O}-$ Overgrowing, $\mathbf{O} \mathbf{L}$ Overgrowing, Loss of agricultural land, $\mathbf{R}$ - Remediation, Recultivation, $\mathbf{t}$ - Industrialization i D Industrialization, Loss of woody vegetation, $\mathbf{t} \mathbf{L}$ - Industrialization, Loss of agricultural land, $\mathbf{u}-$ Urbanization, u D - Urbanization, Loss of woody vegetation, u L - Urbanization, Loss of agricultural land, oz - Other changes/Unclassified

\section{Socio-economic development of the city of Nitra during the period 1949 to 2015}

By 1949, the "building of socialism", era had begun, characterised by the nationalization of private property and creation of cooperatives. Small fields with different usage and owners were grouped into large fields owned by cooperatives. A diverse mosaic of agricultural crops were thus transformed into an intensively managed monoculture, grown over a large area. During this period, the economy was moved to central planning which greatly promoted the development of agriculture and industry in Nitra. In the outskirts of the city, objects of agricultural cooperatives and industrial plants were build. The Plastika Nitra factory was built in 1962 and was one of the largest industrial facilities in the city.

Between the years 1957 and 1967 new structures were built on areas gained by partial or overall sanitation of redundant objects. In the Sixties, the built-up area exceeded the original boundaries of the built-up part of the city, and the city began to grow beyond the river Nitra. The first structures built beyond the river were the College of Agriculture campus (now Slovak University of Agriculture) and the College of Education (now Constantine the Philosopher University). Later, the exhibition center Agrokomplex was built and put into operation in 1974. The construction of panel housing estates began in the Seventies. Chrenová - the first housing estate - was built beyond the river, followed by Klokočina and Diely, situated on the other side of the train line, and again these crossed the borders of the built-up area of the city. The extensive construction of panel housing estates was finished in 1992, while to a lesser degree the completion of individual residential houses has been continuing until now.

By 1989, significant socio-economic changes triggered by the Velvet revolution began as well as the collapse of the socialist establishment. The beginning of the 1990-ties is characterized by permanent changes in law, the level and structure of production and changes to prices and wages. The transformation of agriculture led to fundamental changes in the structure of agriculture in relation to new laws and rules of privatization and a massive restitution of land. After finishing the process of restitution, socialistic national cooperatives began to transform into cooperatives in private property. The majority of owners of restituted land are renting the land out at low prices to big companies (Bičík and Jeleček, 2009). Some 
of the owners of the restituted land divided the arable land into smaller areas intended for individual housing construction. Therefore, new town districts Súdol, Prameň and Nový Lukov dvor (Nitra - Párovské Háje) were created.

Around the turn of the millennium, a new trend in urbanization, industrialization and the intensification of suburbanization had started. This process is connected to the construction of large-scale shopping malls, industrial parks, residential areas and related infrastructure. Construction takes place mostly on high-quality land resources, which leads to loss of fertile agricultural land (Bičík and Jeleček, 2009). The largest industrial park in Nitra is the Nitra-North Industrial Park, which will be fully occupied after the completion of the Jaguar Land Rover car factory and its subcontracted companies. The car factory will cover between 200 and 300 hectares in Nitra city and the adjacent municipalities Lužianky, Čakajovce and Zbehy.

In September 2011, the southern bypass of the city was finished, which is part of the R1 expressway that is part of the express connection between Bratislava and Banská Bystrica cities. Thanks to the R1 expressway, Nitra has in terms of car traffic very good connections with western and central parts of the Slovak Republic.

From 2010 to 2012 there was a slight deceleration of urbanization and industrialization, related to the financial crisis. After the consequences of the financial crisis subsided, and thanks to the inflow of foreign investment in industrial parks, the demand for land and apartments increased again. Urbanization is located mainly in the outskirts of the city, where there are mainly family houses and related infrastructure. On the other hand, mass housing construction consists mainly of brick apartment buildings situated on formerly unused areas within the built-up area of the city. Example are found in apartment complexes in the city district Zobor, in the housing estate Čermán̆ and in the former brewery in the old town. In July 2016, the remediation of the Polygon market started in order to build a multifunctional building (shops, offices, apartments...). Published in September 2016, was the intention to build a multifunctional building with flats 'Promenáda Living Park' involving the reconstruction of the skeleton of the unfinished shopping center City Park near the river in the old town (the construction of City Park has been paused since 2007).

\section{SWOT analysis}

We prepared analysis of strong points, weak points, opportunities and threats (SWOT analysis) for the study area in three domains: social, economic and environmental sphere. The results are presented below.

\section{Social sphere}

SWOT analysis of social sphere is focused on evaluation of human resources, housing, social and health services, education, culture and sport in Nitra.

\section{Strong points $(\mathbf{S})$}

- high amount of skilled labor

- superior level of higher education

- low level of unemployment

- developed network of social housing

- approved community plan of social services in Nitra 2013-2018

- wide offer of social services

\section{Weak points $(\mathrm{W})$}

- negative demographic trends

- rising unemployment level of graduates of secondary schools and universities

- lack of rental housing

- insufficient capacity of facilities for seniors and disabled people (facilities 
- - existence of a University hospital and specialized ambulances

- significant archeological findings, rich network of historic landmarks

- existence of regional competence center for applied research and development in the field of agro-biotechnology (AgroBioTech)

- wide offer of various forms of education

- active sector of sport and physical education

\section{Opportunities (O)}

- creation of new job opportunities for highly qualified labor and graduates of universities

- support for families with children (financial contributions, housing, sufficient capacity of kindergartens...)

- offer of housing for different income and social groups of citizens in cooperation with the private sector

- existence of unused buildings suitable for housing, owned by the city of Nitra

- increase of the quality of housing, renovation of housing stock

- effective use of financial tools of EU structural policy

- revitalization of unused and neglected areas for free-time activities

- restoration of cultural heritage

- better coordination and promotion of cultural activities and cultural heritage of the town

- space for development of cycling and building of cycle routes providing residential, nursing and alternative services)

- reserves in the protection and conservation of the cultural heritage of the city, poor technical condition of some sites, limited resources for the reconstruction of cultural heritage

- insufficient promotion of the cultural offerings and cultural heritage of the city

- unsatisfactory technical condition of buildings and equipment in certain educational institutions

- lack of funds for the maintenance and equipment in schools

- -lack of cooperation between the town and academia

\section{Threats (T)}

- leaving of skilled labor

- negative demographic trends (decrease and aging of citizens)

- rapid aging of the population and the related inability of providers of social and health services and residential facilities for seniors to adapt their capacity

- the deterioration of the health status of the population

- the deterioration of the social situation of inhabitants

- increase in unemployment of risk groups increase of number of maladjusted inhabitants

- increase in crime

- undersized financial resources for education

- inaccessible social and "starter" apartments

- unmanaged suburbanization

- high-quality arable soil sealing

- lack of funding

- abuse of social system

- disappearance of facilities for leisure activities

- end of kindergartens, end or linking primary and secondary schools

- residents not interested in the events in the town 


$$
\text { - } 998 \text { - }
$$

\section{Economic sphere}

SWOT analysis of economic sphere is focused on evaluation of economic development, tourism and traffic in Nitra town.

\section{Strong points (S)}

- favorable geographical location (proximity of borders, capital city and international airports in Bratislava, Vienna and Budapest)

- good connection to road network (R1)

- diversified economic base

- foreign investment (industrial parks)

- increasing intensity of business activity

- a lot of businesses focused on trade and services

- the existence of many scientific research institutions (Slovak Academy of Sciences, universities, National agricultural and Food Centre)

- tradition of exhibition (Agrokomplex)

- high number of historical monuments

- good traffic connectivity

- good conditions for wine tourism

- good conditions for incentive tourism

- reduction of traffic in the town center through construction of the southern bypass

- developed bus transportation (municipal, suburban and longdistance)

\section{Opportunities (O)}

- ample free labor

- support of small and medium business

- preference towards industries based on new approaches and technologies

- connection of education and praxis

- expansion of existing and building of new industrial parks

- gaining of funds from EU programs

- investor interest

- support of residential and incentive tourism

- expanding and improving of services

- better city promotion

\section{Weak points $(\mathrm{W})$}

- low competitiveness of the labor market, lack of attractive job opportunities for highly skilled labor

- high unemployment level of university graduates

- rising share of long-term unemployed insufficient use of business potential opportunities in the cultural and creative sector

- loss-making exhibitions (Agrokomplex)

insufficient promotion of the city insufficient supply of products for tourism

- low capital entry to tourism

- bad connection to rail network (location out of main railway routes)

- unsuitable railway connection

- missing integrated connection between rail and bus transport

- prolonged restoration of bus station

- bad technical state of the roads and pavements

- low attractiveness of municipal bus transport

- excessive preference of individual transport (cars)

- lack of parking spaces

\section{Threats (T)}

- insufficient legal and financial support for small and medium business

- lack of resources for innovation

- ineffective programs focused on the labor market development

- low purchasing power of the population

- the departure of foreign investors and the emergence of "brownfields"

preference towards new industrial buildings at the expense of arable land

- limitation on the possibility of 
- implementation of the potential of the town (exhibition, winery, history...)

- increase in popularity of municipal bus transport

- creation of integrated system of public transport (connection of municipal, railway and bus transport)

- increasing interest in cycling

- expansion of cycle paths and improvement of conditions for cycling

- improvement of technical condition of communications

- construction of communal car parks in housing estates acquisition of resources from EU programs

"extinction" of town centre (relocation of shops and services to shopping malls, extinction of small shops)

- lack of funds

- stagnation in expanding and improving services

complete disappearance of vinery in the region

increasing of individual automobile traffic

poor coverage of area by municipal bus transport (low frequency of services, lack of bus-stops in the outskirts of the town, poor follow-up joints...)

- public deem cycling unsafe

\section{Environmental sphere}

SWOT analysis of environmental sphere is focused on protected areas, waste disposal and quality of air, water and soil.

\section{Strong points (S)}

- existence of protected areas in the cadastre of Nitra

- a high proportion of green areas in the city

- established system of separate collection of waste (paper, glass, plastics, textiles, bio-waste)

- functional urban composting

- operation of 5 collection sites where citizens can submit waste for free

- functional water treatment plant

- approved Action Plan for sustainable energy in Nitra town

- approved Program for improving quality of air for area of air quality management in urban area

\section{Opportunities (O)}

- improvement of the protection and management of protected areas in the cadastral area of the town

\section{Weak points $(\mathrm{W})$}

- deficient protection and care for some protected areas (eg. Rolfesova mine)

- position in the field of environmental hazard (Region 3 environmental quality)

- pollution of surface water and groundwater

- the existence of local pollution sources (e.g. illegal landfills)

- Increased noise levels in some parts of the town (especially around the R1expressway)

- rising degradation and loss of soil

- close proximity of two nuclear power plants (Mochovce, Jaslovské Bohunice) and to the chemical factory (Duslo šal'a)

\section{Threats (T)}

- extinction of protected plants or animals

- rising of costs for waste disposal and 


$$
-1000-
$$

- revitalization of watercourses and their surroundings

- usage of renewable energy sources

- elimination of local sources of pollution

- revitalization and development of public areas

- increase of the level of environmental awareness and behavior of town residents recycling

- increase in the amount of waste

- continuance of degradation and loss of agricultural land, particularly in connection with new construction

- lack of funding

- absence or obsolete state of key policy documents for the creation and protection of environment

\section{Scenarios of possible further development of the town}

We elaborated scenarios of possible further development of the town based on information obtained from Planning documentation of the city of Nitra (ÚPN, 2003) and its additions, Program of economic and social development of Nitra (PHSR, 2016), SWOT analysis, official site of town (www.nitra.sk), press, news websites, analysis of the past land cover development and from our own field survey. Based on the evaluation of this information we decided to elaborate three scenarios: the best possible (progressive), the worst possible (negative) and balanced (realistic).

\section{Negative scenario}

In negative scenario, threats and weak points of the city have a strong influence on the development of the city. This variant expects slowdown or the end of economic growth, which can cause slowdown and a gradual end to industrialization and urbanization. There is a risk of bankruptcy of industrial factories and related formation of brownfields - abandoned and unused industrial areas. It is also expected that the trend of a decreasing and aging population will continue. With this trend a decrease of demand for housing and an increase of demand for social and health services is related (Fig. 3). 


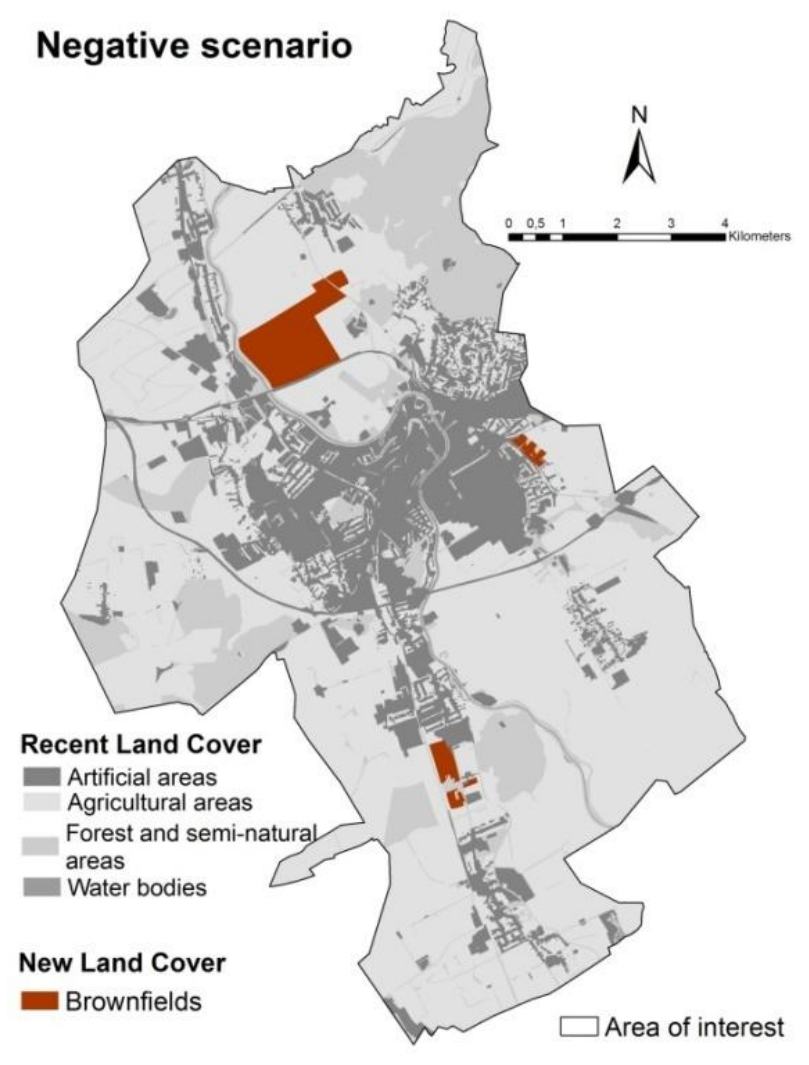

Figure 3. Negative scenario of further development of the city of Nitra

\section{Progressive scenario}

Progressive scenario expects strengthening of strong points and exploiting opportunities, which leads to rapid development of the city in all fields (favorable demographic trend and economic development) and a significant extension of urbanization and industrialization.

Based on this scenario it is possible to expect a significant extension of borders of the city whether due to impact of settlement area, construction of objects of trade and services, spreading of existing industrial facilities or due to the establishment of a new industrial park. This scenario expects a maximum approach to the environmental limits of the territory to achieve the most significant development of the city.

Progressive scenario anticipates filling to full capacity the Nitra-North Industrial Park in the cadastral territory Dražovce, and doubling the area of Nitra-South Industrial Park in the cadastral area Dolné Krškany. Near the Nitra-North Industrial Park there should be situated a newly established industrial park Nitra-West in the cadastral area of the village Lužianky. Additional industrial production is calculated in cadastres of the city parts Chrenová and Vel'ké Janíkovce.

New residents require expansion of accommodation capacities. Therefore, this problem is solved by the construction of a new housing development Párovské Lúky near the industrial park Nitra-North and by significantly spreading individual residential buildings in the outskirts of the city (Fig. 4). 


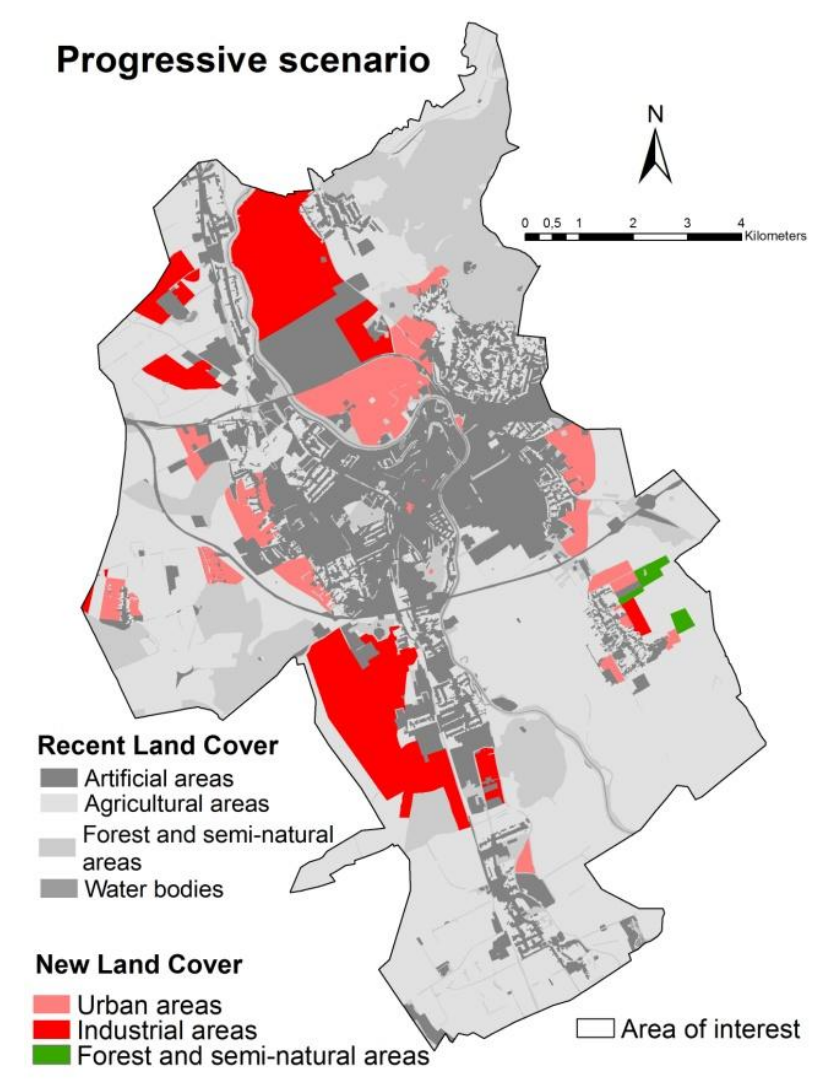

Figure 4. Progressive scenario of further development of the city of Nitra

\section{Realistic scenario}

This scenario aims to achieve a balance between the further development of Nitra and respecting the environmental limits of the area where the city is situated. It supports the development of the strong parts of the city and the exploiting of opportunities. On this basis, the expansion of urban boundaries can be assumed, but not as pronounced as in the case of the progressive scenario.

Realistic scenario is based on information about the confirmed investment (industrial sites, apartment complexes and mass housing development) and on the information gathered by field survey (the construction or sale of land for individual housing construction which has already started).

In housing, this scenario mainly focuses on the spread of individual housing areas on the outskirts of the city, it solves mass housing construction only by the construction of fewer apartment complexes within the urban area.

The capacity of the Nitra-North Industrial Park should be filled mainly thanks to the arrival of Jaguar Land Rover car factory and its subcontracted companies. New industrial factories can create a new Nitra-West Industrial Park situated in cadastral area of the village Lužianky. This new industrial park is connected with the existing NitraNorth Industrial Park and some factories situated on the outskirts of the village Lužianky. Also, several factories announced the spreading of their facilities, therefore the area of Nitra-South Industrial Park in Dolné Krškany should be expanded (Fig. 5). 


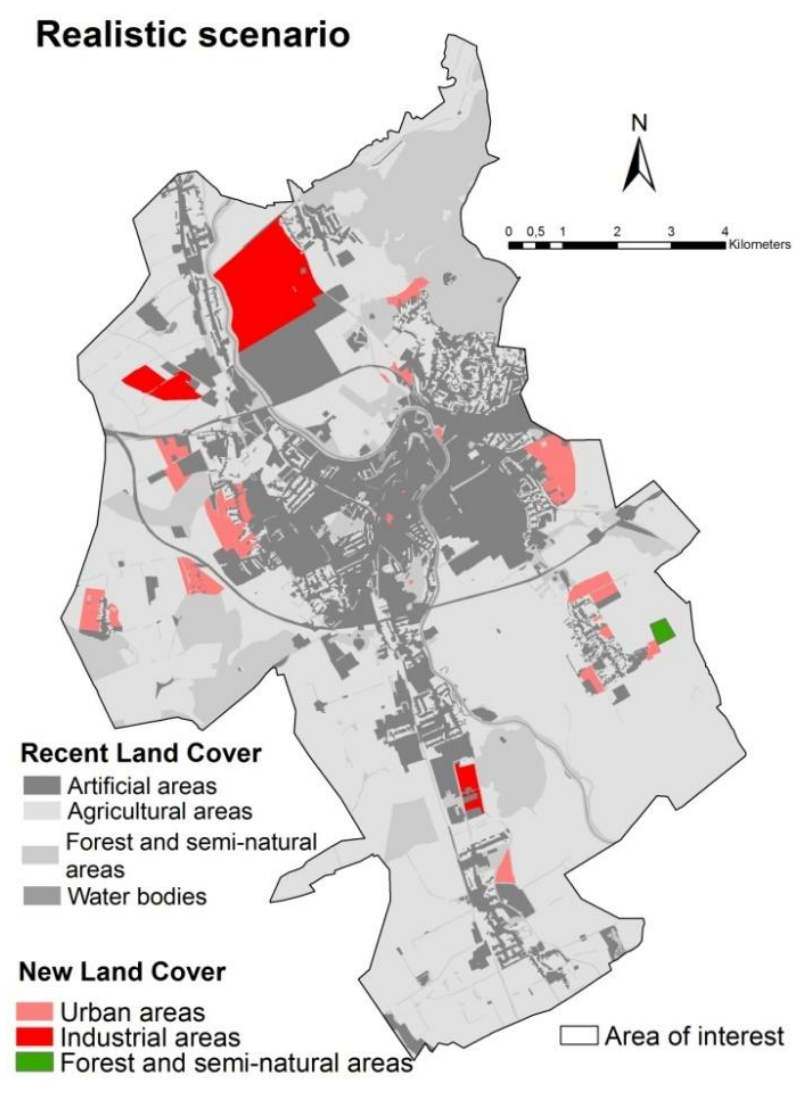

Figure 5. Realistic scenario of further development of Nitra

\section{Discussion}

Spreading of built-up areas is a natural consequence of city development. It is connected with processes of urbanization and industrialization that are accompanied by loss of agricultural land. For a development of the city that protects the environment maintains a good quality of life for its inhabitants, balanced management is needed. This management should be based on information from previous and recent city developments and the dispositions of areas for specific types of usage. This is why detailed mapping and evaluation of land cover and land use changes can be useful in creating good spatial planning documentation.

For modeling of future land use changes are the most commonly used mathematical modeling approaches like Markov Chain, SLEUTH, Dinamica EGO modeling with the Logistic Regression (LR), Regression Tree (RT) and Artificial Neural Networks (ANN) (Berberoglu et al., 2016). However, these approaches do not reflect changes of socioeconomic situation or political (historical socialist planning) and economic changes. This is why we choose approach based on landscape-planning documentation of town, land use changes and our own field survey and created three scenarios of possible further development of the town. Each scenario reflects socio-economic and political situation in different era (see below).

For the future, we plan to verify changes in landscape use 5 years after the full operation of the car race and then use mathematic models to further prediction of landscape changes. 
The structure of land use changes has altered over the years. At the beginning of the period studied, the dominating changes were connected with agriculture production; at present, the dominating changes are connected with urbanization and industrialization. This variability was caused by significant political and economic changes such as "building the socialism", the fall of socialism and following development of market economy. For the future, we plan to verify the changes in landscape use 5 years after the full operation of the car factory and then use mathematical models to further prediction of changes.

The development of industry brings a demand for labor, which has a positive impact on the migration of the population into Nitra. Nevertheless, the population has declined slightly, due to the low or negative natural population growth. This should be positively changed by the arrival of the Jaguar Land Rover car factory, other investors and the related rapid increase of job opportunities in Nitra and its vicinity. Closely related to the increase in job opportunities, is an increasing demand for housing. This demand can be satisfied by a new housing construction in the future. However, it will cause another increase of land use intensity in the studied area. The significant expansion of urban area, mainly due to the construction of the car factory, took place also in Trnava. Land cover and its changes in Trnava town were studied by Kopecká et al. (2015).

At the beginning of period studied, the extensive intensification of agriculture took place and borders of city did not change significantly. If the trend set in this period will continue in the future, it would match the negative scenario of city development. This scenario does not predict spreading of urban areas beyond the built-up areas of the city, it expects conservation and alternatively spreading of agricultural land.

In the Seventies, the construction of panel housing estates began and built-up areas of the city spread significantly. Construction of panel housing estates was ended in the Nineties, when the expansion of individual housing construction begun to prevail. Around the year 2000, the trend of constructing of large-scale shopping malls and industrial parks started. If the trend set in this period will continue in the future, it would match the progressive scenario of the further development of the city. It would bring a significant expansion to the urban area, sealing of agricultural soil and rapid development of industrialization.

At the end of the period studied, significant sealing of agricultural soil due to the construction of industrial parks is clearly visible. Recently, the construction of a car factory in the industrial park which is situated in the northeast part of the cadastral territory appears to be the most obvious change and impact on the landscape in Nitra. Industrial development can have both a positive and a negative impact (Kolejka and Klimánek, 2015). The economic situation appears to be positive because it will reduce the unemployment of the region (Lumnitzer et al., 2015), but in future, the land use change could be the negative. The impact can be identified as direct or indirect. The indirect impact of the automotive industry on the landscape is currently visible in the agricultural landscape. An increase of the biofuel content in fuels (Hammond et al., 2008 ) is reflected in the homogenization of growing crops. This can have a significant impact on the loss of biodiversity and ecosystem services of territories (Bourke et al., 2014; Scheper et al., 2015). The direct impact is related to the sealing and the land use of the most fertile parts of the agricultural landscape. Land use changes may lead to deterioration of water and soil quality (Dai et al., 2017) or loss of landscape character (Hreško et al., 2015; Li and Huang, 2015; Svobodová et al., 2015). 
A similar phenomenon was observed by Kopecká et al. (2015) in relation to the construction of the Peugeot-Citroën car factory in southeast of Trnava. The built-up area of Trnava has thus expanded by 332 ha. In Nitra, the construction of the Jaguar Land Rover car factory began in 2015. This factory will occupy arable land with an area of 200-300 ha. A significant loss of agricultural land was also observed due to the construction of the Kia car factory near Žilina.

Closely related to the increase in job opportunities, is an increasing demand for housing. The current trend of development corresponds to a realistic scenario of further development of the city, but it is inclining towards a progressive scenario due to the rapid spreading of industrial parks and an increased demand for housing.

Acknowledgements. The contribution was prepared within the grant project of Slovak Scientific Grant Agency VEGA no 1/0496/16.

\section{REFERENCES}

[1] Antrop, M. (2000): Background concepts for integrated landscape analysis. - Agric. Ecosyst. Environ. 77: 17-28. DOI: 10.1016/S0167-8809(99)00089-4

[2] Antrop, M. (2005): Why landscapes of the past are important for the future. - Landscape and Urban Planning. 70 (1-2): 21-34. DOI: 10.1016/j.landurbplan.2003.10.002

[3] Berberoğlu, S., Akın, A., Clarke, K. C. (2016) Cellular automata modeling approaches to forecast urban growth for Adana, Turkey: A comparative approach. - Landscape and Urban Planning. 153 (11-27): doi:10.1016/j.landurbplan.2016.04.017

[4] Bičík, I., Jeleček, L. (2009): Land Use and Landscape Changes in Czechia during the period of transition 1990-2007. - Geografie - Sborník České geografické společnosti 4 (114): 263-281

[5] Bossard, M., Feranec, J., Ot'ahel', J. (2000): CORINE land cover technical guide Addendum 2000. Technical report No 40. Copenhagen: European Environment Agency

[6] Bourke, D. et al. (2014): Response of farmland biodiversity to the introduction of bioenergy crops: Effects of local factors and surrounding landscape context. - GCB Bioenergy 6 (3): 275-289. DOI: 10.1111/gcbb.12089

[7] Bugár, G. et al. (2006): Interpretation of changes of secondary landscape structure in relation to biodiversity (in Slovak). - In Hreško, J., Pucherová, Z., Ivan Baláž, I. (eds.) Landscape of Nitra and its surroundings (initial stage of research) (in Slovak). Nitra: Constantine the Philosopher University in Nitra., 56 - 61. ISBN 80-8094-066-5

[8] Cebecauerova, M. (2007): Analysis and assessment of changes of landscape structure (case study of selected part lowland Borska nižina and the mountains Male Karpaty) (in Slovak). - Bratislava: Institute of Geography SAS, Geographia Slovaca 24.

[9] Dai, X., Zhou, Y., Ma, W. \& Zhou, L. (2017): Influence of spatial variation in land-use patterns and topography on water quality of the rivers inflowing to Fuxian Lake, a large deep lake in the plateau of southwestern China. - Ecological Engineering 99: 417-428. DOI: 10.1016/j.ecoleng.2016.11.011

[10] Davis, J.C., Henderson, J.V. (2003): Evidence on the political economy of the urbanization process. - Journal of Urban Economics 53 (1): 98-125. DOI: 10.1016/S0094-1190(02)00504-1 
[11] EEA (European Environmental Agency) (2015): Land take, Retrieved September 14, 2016 - from http://www.eea.europa.eu/data-and-maps/indicators/land-take-2/

[12] Haladová, I., Petrovič, F. (2015): Classification of land use changes (model area: Nitra town). - Ekológia (Bratislava) 34 (3): 249-259. DOI:10.1515/eko-2015-0024

[13] Hammond, G. P., Kallu, S., McManus, M.C. (2008): Development of biofuels for the UK automotive market. - Applied Energy 85 (6): 506-515. DOI: 10.1016/j.apenergy.2007.09.005

[14] Hartvigsen, M. (2014): Land reform and land fragmentation in Central and Eastern Europe. - Land Use Policy 36: 330 - 341. DOI: 10.1016/j.landusepol.2013.08.016

[15] Hersperger, A. M., Bürgi, M. (2009): Going beyond landscape change description: quantifying the importance of driving forces of landscape change in a Central Europe case study. - Land Use Policy 26: 640-648. DOI : 10.1016/j.landusepol.2008.08.015

[16] Heymann, Y., Steenmans, Ch., Croissille, G., Bossard, M. (1994): CORINE land cover. Technical guide. EUR12585. - Luxemburg: Office for Official Publications of the European Communities. 136

[17] Hreško, J., Petrovič, F., Mišovičová R. (2015): Mountain landscape archetypes of the Western Carpathians (Slovakia). - Biodiversity Conservation 24 (13): 3269-3283. doi: 10.1007/s10531-015-0969-6

[18] Hreško, J., Pucherová, Z., Baláž, I. (eds.) (2006): Landscape of Nitra and its surroundings (initial stage of research) (in Slovak). -Nitra: Constantine the Philosopher University in Nitra, ISBN 80-8094-066-5

[19] Ira, V. (2011): Urban and rural land (Editorial in Slovak). - Životné prostredie 3: 113 114 , ISSN 0044-4863

[20] Jarský, V., Pulkrab, K. (2013): Analysis of EU support for managed succession of agricultural land in the Czech Republic. - Land Use Policy 35: 237 - 246. DOI: 10.1016/j.landusepol.2013.05.020

[21] Kanianska, R., Kizeková, M., Nováček, J., Zeman, M. (2014): Land-use and land-cover changes in rural areas during different political systems: A case study of Slovakia from 1782 to 2006. - Land Use Policy 36: 554-566. DOI: 10.1016/j.landusepol.2013.09.018

[22] Kolejka, J., Klimánek, M. (2015): Identification and typology of CZECH post-industrial landscapes on national level using GIS and publicly accessed geodatabases. - Ekológia (Bratislava) 34 (2): 121-136, DOI: 10.1515/eko-2015-0013

[23] Kopecká, M., Rosina, K., Ot’ahel, J., Feranec, J., Pazúr, R., Nováček, J. (2015): Monitoring of development dynamics on local level (Study area of Trnava) (in Slovak). Bratislava: Institute of Geography SAS, Geographia Slovaca 30. ISSN 1210-3519, ISBN 978-80-89580-11-8

[24] Li, Y., Huang, S. (2015): Landscape ecological risk responses to land use change in the Luanhe River Basin, China. - Sustainability (Switzerland) 7 (12): 16631-16652. DOI: $10.3390 /$ su71215835

[25] Lieskovský, J., Kanka, R., Bezák, P., Štefunková, D., Petrovič, F., Dobrovodská, M. (2013): Driving forces behind vineyard abandonment in Slovakia following the move to a market-oriented economy. - Land Use Policy 32: 356-365. DOI: 10.1016/j.landusepol.2012.11.010

[26] Lieskovský, J., Kenderessi, P., Špulerová, J., Lieskovský, T., Koleda, P., Kienast, F., Gimmi, U. (2014): Factors affecting the persistence of traditional agricultural landscapes 
in Slovakia during the collectivization of agriculture. - Landscape Ecology 29: 867-877. DOI: 10.1007/s10980-014-0023-1

[27] Lima, G. T. N. P. D., Hackbart, V. C. D. S., Bertolo, L. S., Santos, R. F. D. (2016): Identifying driving forces of landscape changes: Historical relationships and the availability of ecosystem services in the Atlantic forest. - Ecosystem Services 22 (1): 11-17.

[28] Lumnitzer, E., Beck, Z., Ondrejčák, J., Drahoš, R. (2015): Environmental and economic impacts of the relocation of automobile production. - International Multidisciplinary Scientific GeoConference Surveying Geology and Mining Ecology Management, SGEM, 2 (5): 647-653. DOI: 10.5593/SGEM2015/B52/S23.086

[29] Mander, U., Jongman, R. H. G. (1998): Human impact on rural landscapes in central and northern Europe. - Landsc. Urban Planning 41: 149-153. DOI : 10.1016/S01692046(98)00067-X.

[30] Mišovičová, R. (2008): Landscape-ecological assumptions of the development of Nitra and its contact area (in Slovak). - Nitra: Constantine the Philosopher University in Nitra, ISBN 978-80-8094-212-0

[31] Munteanu, C. et al. (2014): Forest and agricultural land change in the Carpathian region-A meta-analysis of long-term patterns and drivers of change. - Land Use Policy 38: 685-697. DOI: 10.1016/j.landusepol.2014.01.012

[32] Olah, B., Boltižiar, M., Gallay, I. (2009): Transformation of the Slovak cultural landscape since the $18^{\text {th }}$ cent. and its recent trends. - Journal of Landscape Ecology 2 (2): 41-55. DOI: $10.2478 / \mathrm{v} 10285-012-0018-\mathrm{Z}$

[33] Opršal, Z., Kladivo, P., Machar, I. (2016): The role of selected biophysical factors in long-term land-use change of cultural landscape. - Applied Ecology and Environmental Research 14 (2): 23-40, DOI: 10.15666/aeer/1402_023040

[34] Ot’ahel', J., Husár, K., Feranec, J. (2012): Cartographic interpretation of landscape changes, study area Prešov district. - Aktivity v kartografii, Bratislava: Cartographic Society of the Slovak Republic and Institute of Geography SAS, 82-95.

[35] Petrovič, F., Bugár, G., Hreško, J. (2009): The list of landscape elements mappable at the area of Slovakia (in Slovak). - GeoInformation 5: 112-124. ISSN 1336-7234

[36] PHSR (2016) Team of the authors. 2016. Program of the economic and social development in Nitra town, Update for the programming period 2015 - 2023 (in Slovak)

[37] Scheper, J. et al. (2015): Local and landscape-level floral resources explain effects of wildflower strips on wild bees across four European countries. - Journal of Applied Ecology 52 (5): 1165-1175. DOI: 10.1111/1365-2664.12479

[38] Skokanová, H., Falt’an, V., Havlíček, M. (2016): Driving forces of main landscape change processes from past 200 years in central Europe - differences between old democratic and post-socialistic countries. - Ekológia (Bratislava) 35 (1): 50-65. DOI: 10.1515/eko-2016-0004

[39] Skokanova, H. et al. (2012): Development of land use and main land use change processes in the period 1836-2006: case study in the Czech Republic. - Journal of Maps 8 (1): 88-96. DOI: 10.1080/17445647.2012.668768

[40] Smiraglia, D., Ceccarelli, T., Bajocco, S., Perini, L., Salvati, L. (2015): Unraveling Landscape Complexity: Land Use/Land Cover Changes and Landscape Pattern Dynamics (1954-2008) in Contrasting Peri-Urban and Agro-Forest Regions of Northern Italy. Environmental Management 56 (4): 916-932. 
[41] Svobodová, K. Sklenička, P., Vojar, J. (2015): How does the representation rate of features in a landscape affect visual preferences? A case study from a post-mining landscape. - International Journal of Mining, Reclamation and Environment 29 (4): 266276. DOI: $10.1080 / 17480930.2013 .873258$

[42] Tarasovičová, Z., Saksa, M., Blažík, T., Falt’an, V. (2013): Changes in agricultural land use in the context of ongoing transformational processes in Slovakia. - Agriculture 59 (2): 49-64. DOI: 10.2478/agri-2013-0005

[43] UPN. Team of the authors. (2003). Land use plan of the town Nitra, 2003, SANHUMA 90 s.r.o. Nitra

[44] Official website of the town of Nitra: www.nitra.sk. 